\section{Questión}

Periodismo / Comunicación

ISSN 1669-6581

El periodista americano en la Era Digital. Una perspectiva de medio siglo José Antonio Abreu Colombri

Question/Cuestión, Vol. 2, N66, Agosto 2020

ISSNe 1669-6581

https://perio.unlp.edu.ar/ojs/index.php/question/index

IICom-FPyCS-UNLP

DOI: https//doi.org/10.24215/16696581e511

\title{
El periodista americano en la Era Digital. Una perspectiva de medio siglo
}

The American Journalist in the Digital Age. A Half-Century Perspective

José Antonio Abreu Colombri

Doctor en el programa de Estudios Norteamericanos de Ciencias Sociales y Jurídicas de la Universidad de Alcalá, España

abreu.colombri@ucm.es

https://orcid.org/0000-0002-8698-6493

\section{Resumen}

Desde principios de los años 2000, en cuanto a la expansión de los usos digitales de la comunicación se refiere, se ha producido una de las revoluciones más importantes dentro de la historia del periodismo estadounidense. La investigación tiene un arco cronológico muy amplio, pues hace una serie de planteamientos analíticos que tienen su origen en las décadas centrales del 
siglo XX. Las grandes tendencias surgidas en el mundo del periodismo son abordadas desde el punto de vista de la producción informativa. Se hace una especial mención a la irrupción de las redes sociales y las plataformas de Internet sobre el diseño, la difusión y el consumo de la información periodística.

\title{
Palabras clave
}

Periodismo estadounidense, comunicación social, Era Digital.

\begin{abstract}
Since the early 2000s, when it comes to expanding the digital uses of communication, there has been one of the most important revolutions in the history of American journalism. The research has a very wide chronological frame, since it makes a series of analytical approaches that have their origin in the central decades of the 20th century. The major trends that have emerged in the world of journalism are approached from the point of view of news production. Special mention is made of the emergence of social networks and Internet platforms on the design, dissemination and consumption of journalistic information.
\end{abstract}

\section{Key words}

US journalism, social communication, Digital Age.

Históricamente, en los Estados Unidos de América, los grandes informes sobre la situación del periodismo y los profesionales de la información siempre han estado envueltos en cuestiones polémicas, por las implicaciones ideológicas 
que suelen acompañar a la labor periodística. En lo que respecta a la cuestión académica, las investigaciones sobre el estado del periodismo estadounidense también tienen una cierta polémica, es muy raro que unos resultados de investigación cuenten con una aprobación generalizada. Ese fue el caso del estudio sobre "los periodistas estadounidenses" en 2002. Aquel estudio, realizado por miembros de la Universidad de Indiana, hizo brotar reconocimientos de diversa condición ideológica. La estructura y los resultados de dicha investigación fueron el principal venero metodológico para los autores: Lars Willnat, David Weaver y Cliveland Wilhoit.

"The American Journalist in the Digital Age" se gestó en un momento político histórico: la llegada de Trump a la Casa Blanca, en el que se cuestionaba el periodismo tradicional y se discutía vehementemente sobre los efectos de la transformación digital en las formas de elaboración del producto informativo. Los autores del libro, con unas minuciosas técnicas de investigación cuantitativa y entrevistas científicas, abordan los profundos cambios acontecidos durante las últimas décadas en el mundo de la prensa estadounidense. Concretamente, el libro se centra sobre los efectos de las nuevas tecnologías de la comunicación sobre el proceso de producción informativa y la difusión de los mensajes periodísticos. La última década y media es percibida como un período de transformación general dentro de las empresas periodísticas, en el que ha surgido un nuevo contexto de generación de noticias, con múltiples variables comunicativas sobre el impacto de los contenidos sobre la opinión pública. El libro es la decimoséptima publicación de la colección "Mass Communication and Journalism". A pesar de que la editorial Peter Lang Publishing está especializada en temas relacionados con la literatura y la lingüística, tiene una larga trayectoria en proyectos editoriales 
relacionados con la comunicación social, la influencia mediática y la teoría de la información periodística.

El libro se compone de nueve capítulos, incluidas las conclusiones y la introducción. En la parte inicial, existen unos índices de figuras y varias páginas aclaratorias sobre la organización del libro. Mientras que en la parte final, se recoge una amplia sección bibliográfica y dos apéndices documentales, el primero se centra en cuestiones metodológicas y el segundo en los cuestionarios utilizados para llevar a cabo las entrevistas. La introducción se centra en varios ejemplos recientes sobre la importancia de la ética periodística y sus efectos sobre el desempeño de la cobertura informativa, también se adelantan los principales temas de la publicación.

El capítulo segundo, "Basic Characteristics of U.S. Jorunalists", tiene un título muy ilustrativo; se hace un amplio repaso conceptual, temático y de hábitos. "Education and Training" es el título del tercer capítulo; en esas páginas se habla de los principales logros del sistema formativo de los periodistas y las principales deficiencias, con una importante fundamentación estadística. El cuarto capítulo profundiza en el lugar de trabajo y en el desempeño de funciones de los profesionales de la información, bajo el título de "Journalists in the Workplace". La deontología y la normativa profesional es el tema del quinto capítulo: "Profesonalism: Roles, Values and Ethics". Los capítulos sexto y séptimo se encargan de las transformaciones del periodismo motivadas por la incorporación de las mujeres y las minorías: "Woman Journalists" y "Minority Journalists". El octavo capítulo, "Social Media and U.S. Journalism", condensa las páginas más importantes de la investigación, porque hacen referencia a los fenómenos digitales más disruptivos sobre el periodismo tradicional. 
No obstante, al margen de las especificidades de cada capítulo, resulta muy destacable ver como varios temas transversales están presentes en la mayoría de los epígrafes de la investigación. A modo de constante, llaman la atención las alusiones a la situación actual del debate público sobre las acusaciones cruzadas sobre falta de veracidad, noticias falsas y propaganda, en muchos casos con el proceso político que llevó a Trump a la presidencia de fondo. También sorprende el grado de especialización y la profusa documentación que los tres autores despliegan en cada capítulo. Por poner algunos ejemplos concretos, en lo relativo a la educación se hace una prospección que llega a las primeras fases de la fundación nacional de los Estados Unidos. Otro ejemplo destacable sería el de la inserción laboral de los profesionales de la información según su área de formación. El detallado perfil profesional de los periodistas, que se construye en varias partes del libro, a través de estadísticas, se nutre de datos como la filiación religiosa, posición económica, género, identificación política, contribuye a reafirmar algunos estereotipos y a desvelar cierto tipo de cuestiones inopinadas para la mayoría de los consumidores del producto comunicativo. Estas afirmaciones se pueden trasladar a los estudios estadísticos que la obra plantea sobre los gestores empresariales y los propietarios de las corporaciones comunicativas.

La obra enfatiza dos tendencias que son realmente significativas y que se mantienen de forma constante a lo largo de las últimas décadas, por un lado está el continuo declive de la satisfacción laborar entre los periodistas, mientras que por otra parte está la negativa imagen de los profesionales del periodismo entre la ciudadanía estadounidense. También existen algunos elementos positivos, que son convenientemente recogidos en la investigación, a través del incremento de creencias relacionadas con la profesionalidad, la 
responsabilidad social y la deontología del periodista. La comunidad de periodistas estadounidenses tiene conciencia de las malas prácticas y los excesos cometidos en el desempeño de la profesión, esta idea colectiva se manifiesta a través de dos cauces principales: un ejercicio de autocrítica profesional y un ejercicio de denuncia de la presión ejercida sobre los profesionales y de la imposición de tácticas empresariales agresivas. Respecto a los estándares de la ética profesional, los periodistas afirman que los géneros de opinión y de información gozan de buena salud, aunque todo es mejorable, ya que cada generación tiene la obligación de cuestionarse todos los principios teóricos y éticos de su profesión. La inclusión de mujeres y miembros de minorías en las plantillas de medios de comunicación ha supuesto una revolución temática, formal y cultural, en lo que respecta al proceso de construcción de los marcos de trabajo, en los que se generan los productos comunicativos y los mensajes periodísticos. Esta cuestión solo es superada por el impacto de las redes sociales: interactividad, multidifusión, impacto, participación, comercialización y formas de consumo.

Las conclusiones son un ejemplo de síntesis estadística y de interconexión temática: perfiles de consumidores, pautas de consumo, libertad de pensamiento, problemas surgidos entre los representantes políticos y las creencias religiosas mayoritarias, consumo de contenidos, identificación mediática, trabajo informativo, corporativismo empresarial, roles profesionales, ética periodística, autocrítica y profesionalismo, clasificación de fuentes, lealtades profesionales, redes sociales, canales de amplificación de mensajes, intrusismo profesional, etc. La compilación bibliográfica puede ser la clave de bóveda de cualquier investigador que precise adentrarse en los estudios periodísticos estadounidenses. Los dos apéndices documentales revelan la 
minuciosa tarea de investigación realizada durante toda la elaboración del libro. Es llamativo el volumen de documentos que han tenido que clasificar los autores, para establecer los fundamentos cuantitativos y los desarrollos interpretativos de la investigación.

\section{Bibliografía}

Willnat, Lars., Weaver, David. y Wilhoit, Cleveland. (2017). The American Journalist in the Digital Age. A Half-Century Perspective. Nueva York: Peter Lang Publishing, pp. 443. ISBN: 978-1-4331-2828-8 